\title{
Effects of ultrasonically activated irrigants with or without surfactant on smear layer removal after post space preparation
}

\author{
Sevinc Aktemur Turker, Zeliha Yilmaz, Bahar Ozcelik, Melahat Gorduysus, Emre Altundasar.
}

DDS, PhD. Department of Endodontics, Faculty of Dentistry, Hacettepe University, Ankara, Turkey.

Correspondence:

Department of Endodontics,

Faculty of Dentistry,

Hacettepe University, 06100

Sihhiye/Ankara, Turkey.

E-mail address: sevincaktemur@hotmail.com

Turker SA, Yilmaz Z, Ozcelik B, Gorduysus M, Altundasar E. Effects of ultrasonically activated irrigants with or without surfactant on smear layer removal after post space preparation. J Clin Exp Dent. 2012;4(5):e260-5. http://www.medicinaoral.com/odo/volumenes/v4i5/jcedv4i5p260.pdf

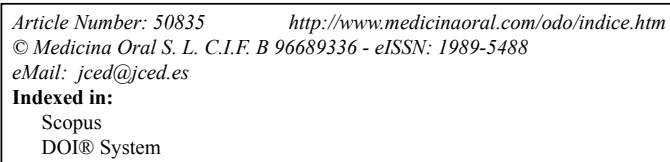

\begin{abstract}
The aim of this study was to compare the effects of different $\mathrm{NaOCl}$ and EDTA formulations with/without ultrasonic use on smear layer removal and root canal surface characteristics after post space preparation.

Study design: After post space preparations, forty-six teeth were subjected to different post space irrigation regimes; G1, 17\% EDTA; G2, 17\% EDTA+Ultrasonic activation; G3, EDTA-T; G4, EDTA-T+Ultrasonic activation; G5, NaOCl; G6, NaOCl+Ultrasonic activation. Specimens were examined under scanning electron microscope and scored for debris and smear layer removal and dentinal tubule opening and statistically analyzed with Kruskal Wallis and Dunn's test. Significance value was set at $p<0.05$.

Results: EDTA and EDTA-T groups showed significantly better efficiency than the other groups in the each parts of the samples in terms of smear layer removal $(\mathrm{p}<0.05)$. In terms of dentinal tubule opening, EDTA, EDTA+Ultrasonic and EDTA-T groups had significantly better efficacy than the other groups in the middle and coronal parts of the samples $(\mathrm{p}<0.05)$.

Conclusions: Ultrasonic activation did not significantly improve the efficiency of the irrigants.
\end{abstract}

Key word: Irrigation, post space preparation, smear layer, surfactant, ultrasonics. 


\section{Introduction}

In recent years, fiber posts and resin-based luting cements, which lead to fewer and favorable root fractures due to their dentin-matching mechanical characteristics, have been recommended to rebuild endodontically treated teeth (1). Adhesive techniques and resin based luting materials enhance bonding of posts to dentin, which is necessary for the long term success of the restoration. Previous studies have emphasized the importance of smear layer removal and formation of the resin-dentin interdiffusion zone to improve bonding efficiency (2, $3)$.

The initial step of all post and core restorations is removal of the root filling material with drills to create a suitable post space. Mechanical preparation of the post space with drills inevitably results in debris and smear layer formation containing remnants of gutta-percha and sealer (4). Failure to remove this smear layer might interfere with effective bonding of resins. Various chemical solutions or chelators, alone or combined with ultrasonics, have been evaluated for their smear layer removal efficiency in root canals and post spaces (5-8). Ethylenediaminetetraacetic acid (EDTA) is one of the most effective chelating agents for removing the inorganic debris of smear layer from the root canal. EDTA treated dentinal walls have better adhesion with filling materials (9). Detergents have been added to EDTA in order to increase dentinal penetration of the solution. This addition reduces the surface tension of the irrigant, facilitating the wetting of the entire root canal wall, and thereby increasing the ability of the chelators to penetrate to the dentin (10). One of these chelators is EDTA-T having low surface tension due to addition of a surfactant. Tasman et al (11) and Yilmaz et al (12) demonstrated that the EDTA with surfactant has lower surface tension value than other solutions.

To the authors' knowledge, only a few studies have been performed on the efficacy of smear layer and debris removal using different irrigants after post space preparations $(13,14)$. This in vitro study evaluated the effects of different irrigation regimens with EDTA and EDTA-T solutions on smear layer removal and characteristics of the canal surface after post space preparation and to study whether or not additional ultrasonic irrigation has any effect on smear layer removal.

\section{Material and methods}

Forty-six extracted human mandibular premolar teeth were used. The crown of each tooth was removed at the cementoenamel junction perpendicular to the long axis of the root so that each root was approximately $14 \mathrm{~mm}$ in length. The canals were instrumented using a crown-down technique with rotary ProTaper instruments rotated at $250 \mathrm{rpm}$ (Dentsply, Maillefer, Ballaigues, Switzerland) to size F4. The canals were irrigated with $2 \mathrm{ml} 2.5 \%$ sodium hypochlorite $(\mathrm{NaOCl})$ between each file. After completion of the instrumentation, $5 \mathrm{ml}$ $2.5 \% \mathrm{NaOCl}$ was applied as final flush and then the root canals were dried with \#30 sterile paper points (Spident, Incheon, Korea).

Prepared root canals were obturated using a resin sealer (AH 26; Dentsply Detrey, Konstanz, Germany) and lateral compaction of gutta-percha. The teeth were then immersed in the freshly mixed thymol solution for 2 weeks to let the resin sealer polymerize completely. The guttapercha was removed and a $10 \mathrm{~mm}$ post spaces were prepared with the kit drills of the double taper radiopaque translucent fiber posts (D.T. Fiber Post, Bisco, USA) taking care to leave at least $4 \mathrm{~mm}$ of gutta-percha to preserve the apical seal. The teeth were randomly divided into six experimental groups $(\mathrm{n}=7)$. Six groups were formed regarding to irrigation regimens as follows;

- Group 1; irrigation with 17\% EDTA,

- Group 2; irrigation 17\% EDTA with ultrasonic activation for 60 seconds,

- Group 3; irrigation EDTA-T ((17\% EDTA + 1.25\% sodium lauryl ethersulfate [Sigma-Aldrich]),

- Group 4; irrigation EDTA-T with ultrasonic activation for 60 seconds,

- Group 5; irrigation $\mathrm{NaOCl}$,

- Group 6; irrigation $\mathrm{NaOCl}$ with ultrasonic activation for 60 seconds. Four teeth were used for control group and only irrigated with distilled water.

Root dentine surfaces were irrigated with $10 \mathrm{ml}$ of each irrigant for 60 seconds And then to avoid the prolonged effect of these irrigants $10 \mathrm{ml}$ distile water was used as a final jet. For groups with ultrasonic activation, ISO 15 ultrasonic K-file at Suprasson P-50 machine (Satelec, Merignac Cedex, France) was used for all teeth (6). \#15 ultrasonic K-file placed $1 \mathrm{~mm}$ from the apical end of post space and in consideration of the diameter of post space, the power setting was adjusted to 4 .

After post space irrigation, teeth were grooved along the buccal and lingual surfaces by using a diamond disc at low speed and split longitudinally with a chisel and mallet into two halves. While during this procedure we ensured that the diamond disc doesn't touch on the root canal walls. These halved specimens were dehydrated in ethanol $(50 \%, 75 \%, 95 \%$, and $100 \%)$ and then dried in desiccators for 24 hours. Each specimen was gold sputtered to achieve a conductive coating and then examined with a scanning electron microscope (SEM), (JEOL JSM-6400, Japan) at 1-, 4.5-, and 8-mm levels from the apical to the coronal third of the post space (13).

The specimens were coded and examined in a blind manner by 2 observers. Separate evaluations were performed for smear layer and dentinal tubules opening at x1000 magnification. For each tooth, the mean marks of debris and dentinal tubules opening were calculated separately at three parts of radicular dentin (coronal, middle, and 
apical third). In order to evaluate the compatibility of two observers, kappa factor was checked. Compatibility was found as $94 \%$.The average of the observers' scorings for each section was used for the statistical analysis.

The amount of debris was marked from 0 to 2 (14).

0 : No debris particles

1: Few debris particles, with maximum diameter of less than $20 \mu \mathrm{m}$,

2: Large amount of debris particles, with diameter greater than $20 \mu \mathrm{m}$.

The number of dentinal tubule opening was marked from 0 to 2 ;

0 : All dentinal tubules open, without debris, smear layer, and sealer/gutta-percha residue

1: Some dentinal tubules open, with a thin smear layer, debris, and sealer/gutta-percha residue covering these opening

2: All dentinal tubules blocked by thick smear layer with debris and sealer/gutta-percha residue.

Statistical differences among the experimental groups were analyzed using Kruskal Wallis test. Multiple comparisons performed by Dunn's test. Significance value was set at $\mathrm{p}<0.05$.

\section{Results}

The median rank of debris and dentinal tubules opening marks at different thirds of root canals was recorded to evaluate the differences within each group (Table 1). In terms of smear layer removal; control group, groups with ultrasonic activation and $\mathrm{NaOCI}$ group were less efficient than the other groups in the apical parts of the samples $(p<0.05)$. EDTA and EDTA-T groups showed significantly better efficiency than the other groups in the each parts of the samples $(p<0.05)$. However these two groups had no significantly difference $(\mathrm{p}>0.05)$.

In terms of dentinal tubule opening, EDTA, EDTA+Ultrasonic and EDTA-T groups had significantly better efficacy than the other groups in the middle and coronal parts of the samples $(\mathrm{p}<0.05)$. In the apical part, only EDTA+Ultrasonic and EDTA-T groups showed significantly higher efficacy when compared with other groups ( $\mathrm{p}<0,05)$.

Irrigation with ultrasonic activation (Groups 2, 4, and
6) had no additional significant effect on smear layer removal and dentinal tubule opening when compared with those with respective irrigation without ultrasonic activation ( $\mathrm{p}>0.05)$. However among the ultrasonic groups, only EDTA+Ultrasonic group showed better efficiency in the middle and coronal part of the samples in terms of both dentinal tubule opening and smear layer removal. When root canal surfaces were compared on the removal of smear layer at each level, there was a significant difference at the coronal parts of the root canal surfaces, when compared with apical and middle thirds $(\mathrm{p}<0.05)$. The least amount of debris remained at the coronal thirds. Similarly, more and larger dentinal tubule was visible at the coronal part, when compared with other parts of the root canal surfaces $(p<0.05)$ (Fig. 1, Fig. 2).

\section{Discussion}

Cleaning surfaces of canal walls after post space preparation has been reported to be a critical procedure for optimal post retention (15). When fiber post and resin luting systems are used to restore endodontically treated teeth, the gutta-percha remnants and smear layer must completely be eliminated from the root canal in order to create ideal conditions for optimal adhesion to root canal dentin. Currently, a final irrigation sequence with a chelating agent, such as EDTA is recommended to remove the inorganic components of the smear layer (16). Saito et al (17) found that shortened irrigation time with EDTA less than 1 minute could significantly decrease smear layer removal. Thus, in our study, EDTA and $\mathrm{NaOCl}$ were used for irrigation separately, with a 1-minute irrigating time.

Surface tension can be defined as the force between molecules that produces a tendency for the surface area of the liquid to decrease. This force tends to prevent the spread of a liquid over a surface or limit its ability to penetrate a capillary tube (18). Reducing surface tension of an endodontic irrigating solution improves its wetting ability (19) and spread into narrow canals (20). Therefore it can be speculated that a surfactant added endodontic irrigating solution, has lower surface tension and this reduction of its surface tension might improve its efficacy in the apical region of the root canal. Thus, it

\begin{tabular}{llllllll}
\hline \multirow{2}{*}{ Group } & \multicolumn{3}{l}{ Smear Layer and Debris } & \multicolumn{4}{l}{ Dentinal Tubule Opening } \\
\cline { 3 - 8 } & $\mathbf{n}$ & Apical & Middle & Coronal & Apical & Middle & Coronal \\
EDTA & 7 & $1,000 \pm 0,516$ & $1,000 \pm 0.408$ & $1.000 \pm 0.000$ & $2.000 \pm 0.408$ & $1.000 \pm 0.516$ & $1.000 \pm 0.000$ \\
EDTA+ULTRASONIC & 7 & $2.000 \pm 0.516$ & $1.000 \pm 0.408$ & $1.000 \pm 0.408$ & $1.000 \pm 0.632$ & $1.000 \pm 0.752$ & $1.000 \pm 0.408$ \\
EDTA-T & 7 & $1.000 \pm 0.516$ & $1.000 \pm 0.516$ & $1.000 \pm 0.408$ & $1.000 \pm 0.516$ & $1.000 \pm 0.000$ & $1.000 \pm 0.516$ \\
EDTA-T+ULTRASONIC & 7 & $2.000 \pm 0.408$ & $2.000 \pm 0.516$ & $2.000 \pm 0.516$ & $2.000 \pm 0.516$ & $2.000 \pm 0.516$ & $2.000 \pm 0.836$ \\
NaOCI & 7 & $2.000 \pm 0.000$ & $2.000 \pm 0.000$ & $1.500 \pm 0.547$ & $2.000 \pm 0.000$ & $2.000 \pm 0.000$ & $2.000 \pm 0.000$ \\
NaOCI+ULTRASONIC & 7 & $2.000 \pm 0.000$ & $2.000 \pm 0.408$ & $2.000 \pm 0.516$ & $2.000 \pm 0.000$ & $2.000 \pm 0.000$ & $2.000 \pm 0.000$ \\
CONTROL & 4 & $2.000 \pm 0.000$ & $2.000 \pm 0.000$ & $2.000 \pm 0.000$ & $2.000 \pm 0.000$ & $2.000 \pm 0.000$ & $2.000 \pm 0.000$
\end{tabular}

Table 1. Median and Standard Deviation of smear layer, debris and dentinal tubule opening at three levels of root canal dentin surface after cleaning with different irrigation solutions. 

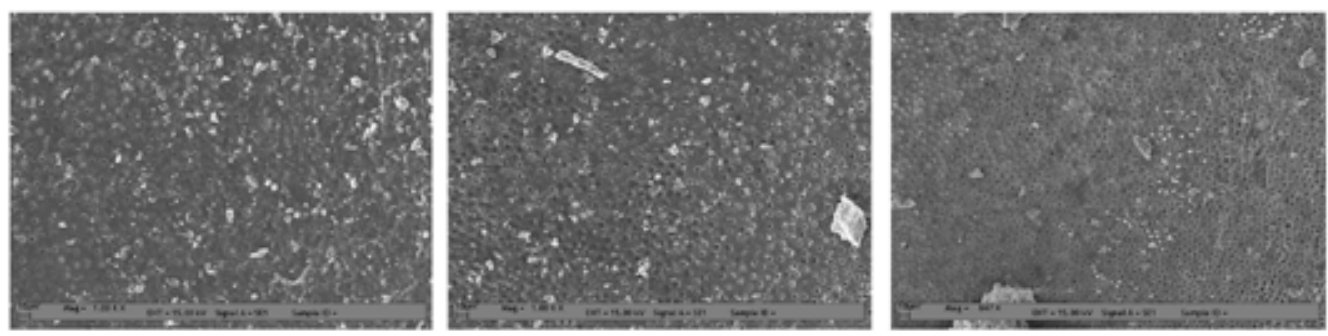

EDTA
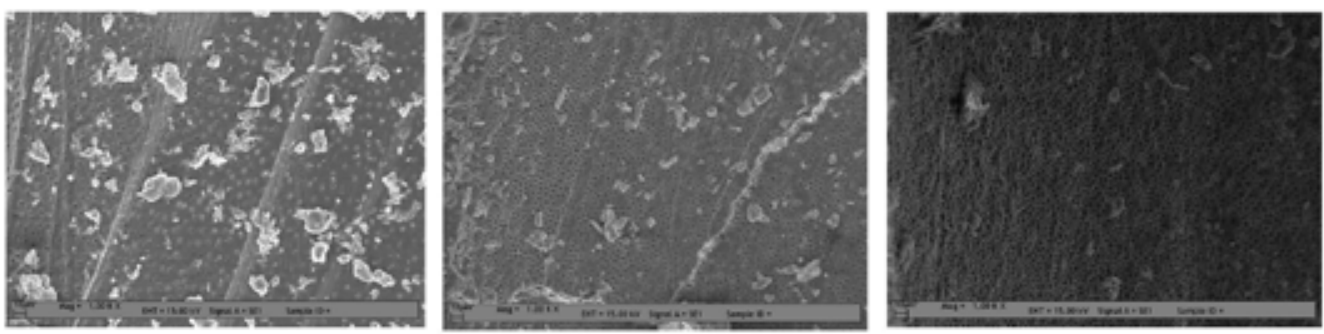

EDTA-T

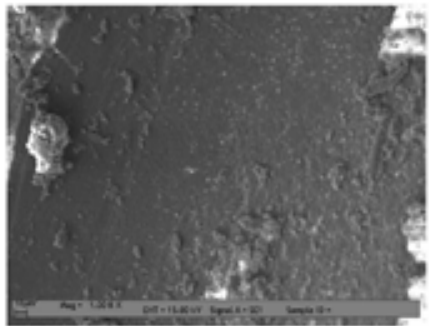

Apical

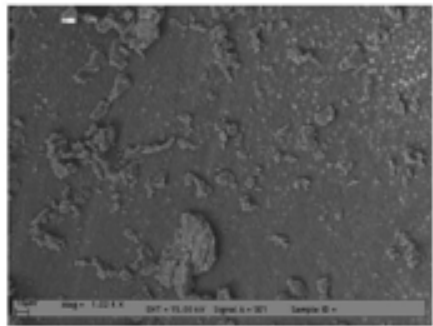

Middle

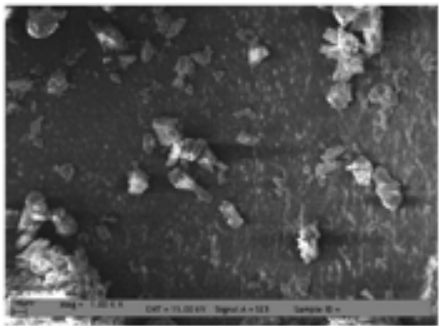

Coronal

Fig. 1. Representative SEM photomicrographs showing the apical, middle, and coronal levels of root canal dentin surface in EDTA, EDTA-T and NaOCI groups $(1,000 x)$
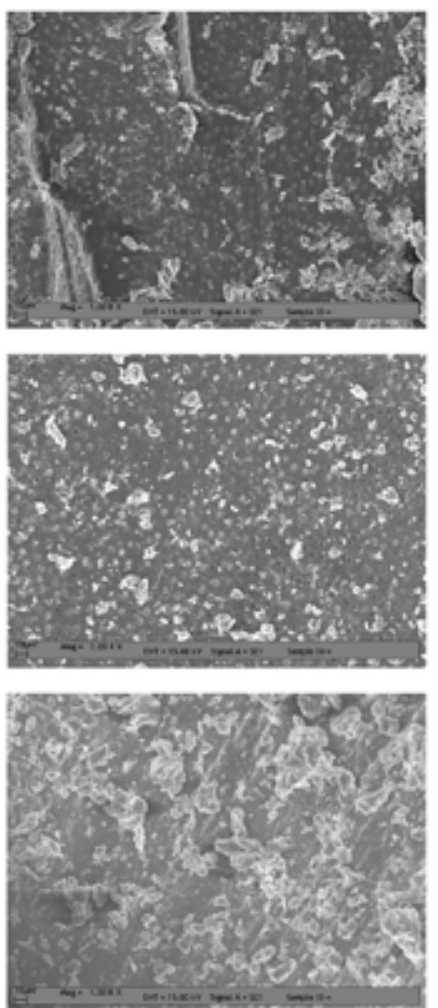

Apical
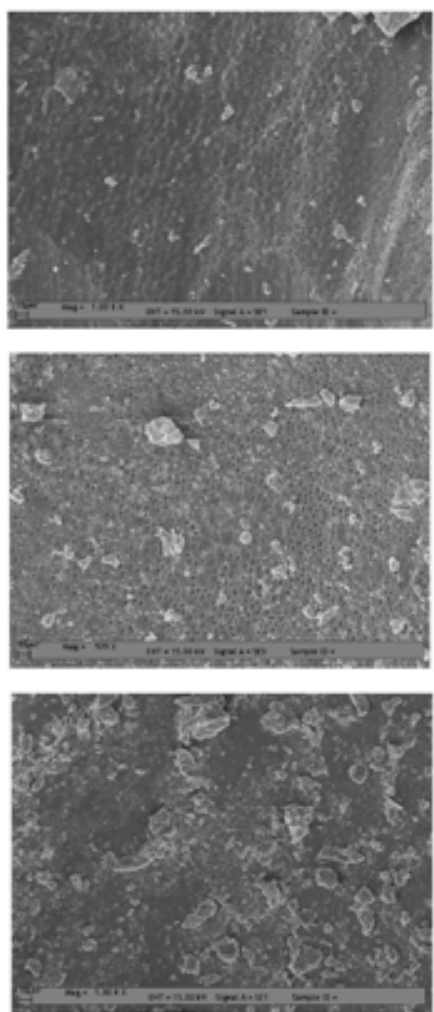

Middle

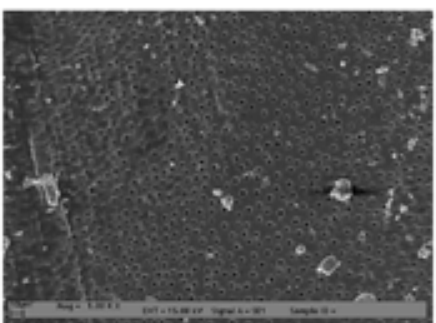

EDTA+

Ultrasonic

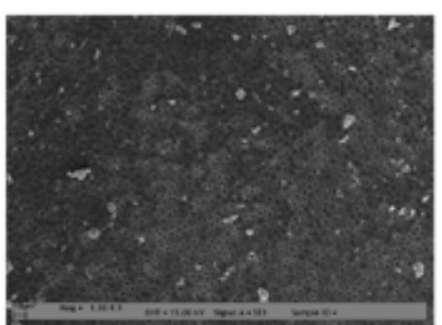

EDTA-T+

Ultrasonic

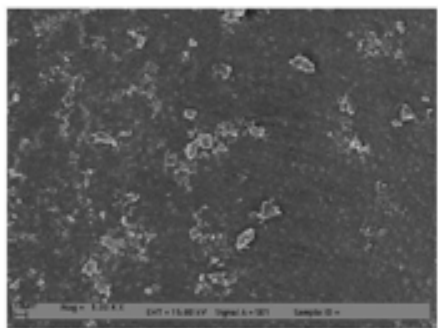

Coronal

Fig. 2. Representative SEM photomicrographs showing the apical, middle, and coronal levels of root canal dentin surface in EDTA + ultrasonic, EDTA-T + ultrasonic and NaOCI + ultrasonic groups $(1,000 x)$. 
can be possible that low-surface-tension EDTA solutions might improve the adhesion properties of root canal dentin. However, our experiments showed that adding a detergent failed to improve the performance of EDTA in terms of smear layer removal. This finding is in accordance with a recent study (6) which demonstrated that addition of surfactants to EDTA did not result in better smear layer removal compared to EDTA alone. According to Zehnder et al (21) calcium chelating ability of an endodontic chelator did not improve with addition of a surfactant to reduce the surface tension. According to Zehnder's study it may not be necessary to add a wetting agent to a chelator solution to improve its effectiveness in removing inorganic smear layer components. Sampaio et al (22) showed that sodiumlaurylsulphate was ineffective in removing the smear layer alone compared to EDTA groups. Another study by Sampaio demonstrated no significant difference between EDTA and EDTA-T groups (23). Although use of detergents seems beneficial to remove bacteria and toxins from the root surface, they do not play a major role for removal of smear layer (24). In a study by Scelza et al (25), higher debris scores were found with EDTA-T groups regardless of application time.

In general, analysis of the dentinal wall of all the specimens in the experimental groups demonstrated that cleaning of the coronal and middle thirds of these surfaces had been effective. When compared with the apical third, it is possible that the size of the canals in these thirds, allowed better circulation and action of the irrigating solution, making complete removal of the smear layer possible. Such results are in agreement with those of various authors $(26,27)$ who have also observed an effective cleaning action on these thirds even when different quantities of solutions and times of irrigation were employed. Due to the small diameter of root canals, it is often difficult for the irrigating solutions to reach the apex of the tooth.

In the present study, ultrasonic activation of the irrigation did not have any additional effect on the smear layer removal and dentinal tubule opening. This result was in accordance with the findings presented by Hulsmann et al (16) and Xin-Hua Gu et al (14) who reported that ultrasonic activation could not improve the cleaning effect of irrigation. However, other researchers reported that ultrasonic activation had a supportive effect on smear layer removal during endodontic treatment $(6,8,29)$. These different effects of ultrasonic activation might be caused by the different diameters of the post space and the root canal (14). Ultrasonic activation might have only limited influence on the radicular dentin surface of the post space, which had a larger diameter than the root canal. As a result of the small diameter of the post space, it may be difficult for the irrigating solutions to reach the apical root region and action of ultrasonic.
With the limitations of this study, results show that irrigation with EDTA without ultrasonic activation could effectively remove the smear layer and open dentinal tubules after post space preparation. However, addition of surfactants to EDTA in EDTA-T did not result in better smear layer removal, when compared with EDTA alone. Ultrasonic activation did not have any additional effect on smear layer removal.

\section{References}

1. Gu XH, Kern M. Fracture resistance of crowned incisors with different post systems and luting agents. J Oral Rehabil. 2006;33:91823.

2. Pashley DH, Ciucchi B, Sano H, Horner JA. Permeability of dentin to adhesive agents, Quint Int. 1993;24:618-31.

3. Chappell, RP. Cobb CM, Spencer P,Eick JD. Dentinal tubule anastomosis: a potential factor in adhesive bonding?. J Prost Dent. 1994;72:183-8.

4. Serafino C, Gallina G, Cumbo E, Ferrari M. Surface debris of canal walls after post space preparation in endodontically treated teeth: a scanning electron microscopic study. Oral Surg Oral Med Oral Pathol Oral Radiol Endod. 2004;97:381-7.

5. Torabinejad M, Khademi AA, Babagoli J, Cho Y, Johnson WB, Bozhilov K, Kim J et al. A new solution for the removal of the smear layer. J Endod. 2003;29:170-5.

6. Lui JN, Kuah HG,Chen NN. Effect of EDTA with and without surfactant or ultrasonics on removal of smear layer. J Endod. 2007;33:472-5.

7. Chopra S, Murray PE, Namerow KN. A scanning electron microscopic evaluation of the effectiveness of the F-file versus ultrasonic activation of a K-file to remove smear layer. J Endod. 2008;34:1243-5.

8. Carvalho AS, Camargo $\mathrm{CH}$, Valera MC, Camargo SE, Mancini $\mathrm{MN}$. Smear layer removal by auxiliary chemical substances in biomechanical preparation: a scanning electron microscope study. J Endod. 2008;34:1396-400.

9. Serper A, Calt S. The Demineralizing effects of EDTA at Different Concentrations and Ph. J Endod. 2002;28:501-2.

10. De-Deus G, Reis C, Fidel S, Paciornik S. Dentine demineralization when subjected to EDTA with or without various wetting agents: a co-site digital optical microscopy study. Int Endod J. 2008;41:27987.

11. Taşman F, Cehreli ZC, Oğan C, Etikan I. Surface tension of root canal irrigants. J Endod. 2000;26:586-7.

12. Yilmaz Z, Basbag B, Buzoglu HD, Gümüsderelioglu M. Effect of low-surface-tension EDTA solutions on the wettability of root canal dentin. Oral Surg Oral Med Oral Pathol Oral Radiol Endod. 2011;111:109-14.

13. Coniglio I, Magni E, Goracci C, Radovic I, Carvalho CA, Grandini S, et al. Post space cleaning using a new nickel titanium endodontic drill combined with different cleaning regimens. J Endod. 2008:34:83-6.

14. Gu XH, Mao CY, Kern M. Effect of different irrigation on smear layer removal after post Space Preparation. J Endod. 2009;35:583-6.

15. Boone KJ, Murchison DF, Schindler WG. Walker WA 3rd.Post retention: the effect of sequence of post-space preparation, cementation time, and different sealers. J Endod. 2001;27:768-71.

16. Hülsmann M, Heckendorff M, Lennon A. Chelating agents in root canal treatment: mode of action and indications for their use. Int Endod J. 2003;36:810-30.

17. Saito K, Webb TD, Imamura GM, Goodell GG. Effect of shortened irrigation times with $17 \%$ ethylene diamine tetra-acetic acid on smear layer removal after rotary canal instrumentation. J Endod. 2008;34:1011-14.

18. Philips RW. Skinner's 2 Science of Dental Materials. Philadelphia PA. Sounders. 1991. 
19. Glantz PO, Hansson L. Wetting of dentine by some root canal medicaments. Odontol Revy. 1972;23:205-10.

20. Abou-Rass M,Patonai FJ Jr. The effects of decreasing surface tension on the flow of irrigating solutions in narrow root canals. Oral Surg Oral Med Oral Pathol. 1982;53:524-6.

21. Zehnder M, Schicht O, Sener B, Schmidlin P. Reducing surface tension in endodontic chelator-solutions has no effect on their ability to remove calcium from instrumented root canals. J Endod 2005;31:590-2.

22. Sampaio JE, Theodoro LH, Correa MA, Mendes AJ. A comparative SEM study of smear layer removal by detergents and EDTA on the root surface. Int J Periodontics Restorative Dent. 2005;25:157-63.

23. Sampaio JE, Rached RS, Pilatti GL, Theodoro LH, Batista LH. Effectiveness of EDTA and EDTA-T brushing on the removal of root surface smear layer. Pesqui Odontol Bras. 2003;17:319-25.

24. Lindskog S, Blomlöf J, Blomlöf L. Root surface conditioning. In: Hugoson A, Lundgren D, Lindgren B. Guided periodontal tissue regeneration. Stockolm: Gothia. 1995:127-38.

25. Scelza MF, Pierro V, Scelza P, Pereira M. Effect of three different time periods of irrigation with EDTA-T, EDTA, and citric acid on smear layer removal. Oral Surg Oral Med Oral Pathol Oral Radiol Endod. 2004;98:499-503.

26. Baumgartner JC, Mader CL. A scanning electron microscopic evaluation of four root canal irrigation regimens. J Endod. 1987;13:147-57.

27. Abbott PV, Heijkoop PS, Cardaci SC, Hume WR, Heithersay GS. An SEM study of the effects of different irrigation sequences and ultrasonics. Int Endod J. 1991;24:308-16.

28. Guerisoli DM, Marchesan MA, Walmsley AD, Lumley PJ, Pecora JD. Evaluation of smear layer removal by EDTAC and sodium hypochlorite with ultrasonic agitation. Int Endod J. 2002;35:41821.

29. Gutarts R, Nusstein J, Reader A, Beck M. In vivo debridement efficacy of ultrasonic irrigation following hand-rotary instrumentation in human mandibular molars. J Endod. 2005;31:166-70. 